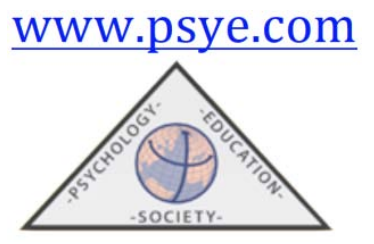

(C) Psychology, Society, \& Education, 2017. Vol. 9(1), pp. 89-103

ISSN 2171-2085 (print) / ISSN 1989-709X (online)

\title{
The relation between math self-concept, test and math anxiety, achievement motivation and math achievement in 12 to 14-year- old typically developing adolescents
}

\author{
Hannelotte L. TIMMERMAN, Sylke W.M. TOLL \& Johannes E.H. VAN LUIT \\ University of Utrecht, The Netherlands
}

(Received on April 3, 2016; Accepted on June 14, 2016)

\begin{abstract}
This study examines the relation between math self-concept, test and math anxiety, achievement motivation, and math achievement in typically developing 12 to 14-year-old adolescents ( $N=108$ ) from a school for secondary education in the Netherlands. Data was obtained using a math speed test, achievement motivation test, and the math experience questionnaire. A significant positive correlation was found between math self-concept and math achievement in all four math domains (measurement, relations, numbers, and scale), as well as automatized math skills. Furthermore, there was a significant negative correlation between math anxiety and math achievement in the math domain "scale". Math anxiety was not a mediator in the correlation between math self-concept and math achievement. There was no correlation between achievement motivation, test anxiety, and math achievement. Regression analyses indicated that math self-concept was the only variable that accounted for a significant unique proportion of variance in math scores. Together, these results suggest that stimulating positive feelings and beliefs of students in their own competence in math may lead to better math achievement.
\end{abstract}

Keywords:math self-concept, test anxiety, math anxiety, achievement motivation, math achievement

La relación entre el autoconcepto matemático, la ansiedad ante las matemáticas y la motivación de logro en adolescentes de 12 a 14 años

RESUMEN: En este estudio se examinó la relación entre el auto concepto matemático, la ansiedad ante los exámenes en matemáticas, la motivación de logro y el rendimiento matemático en adolescentes de desarrollo estándar $(\mathrm{N}=108)$ de 12 a 14 años de un centro de educación secundaria en Holanda. Los datos fueron obtenidos a partir de una prueba de velocidad de resolución matemática, un test de motivación de logro y un cuestionario sobre su experiencia con las matemáticas. Se encontró una correlación positiva entre el auto concepto matemático y los resultados en matemáticas en los cuatro dominios evaluados (medidas, relaciones, numeración y escalas), así como con las habilidades matemáticas automatizadas. Igualmente se encontraron correlaciones negativas significativas entre la ansiedad ante las matemáticas y los resultados en esta materia para las tareas de escalas. La ansiedad matemática no resultó ser un mediador en la correlación entre auto concepto matemático y los resultados en matemáticas. Tampoco se encontró correlación entre motivación de logro, la ansiedad 
ante los exámenes y los resultados en matemáticas. El análisis de regresión indicó que el autoconcepto matemático fue la única variable que explicaba una proporción significativa de la varianza en los resultados en matemáticas. Teniendo en cuenta estos datos, se sugiere que la estimulación de creencias y sentimientos positivos de los estudiantes sobre su propia competencia en matemáticas, puede mejorar el rendimiento en esta materia.

Palabras clave: auto concepto matemático, ansiedad ante los exámenes, ansiedad a las matemáticas, motivación de logro, resultados en matemáticas

Correspondence:J.E.H. Van Luit. Faculty of Social and Behavioral Sciences, Department of Pedagogical and Educational Sciences, Utrecht University, P.O. Box 80140, NL 3508 TC Utrecht, The Netherlands e-mail: j.e.h.vanluit@uu.nl

Many children experience math difficulties in primary school and develop fear and demotivation. In the short term, math difficulties may lead to avoiding math tasks; in the long term math difficulties can influence their school career (Passolunghi, 2011). Children's capacity to improve their math skills depends, among other things, on their feelings of being comfortable with math in general (Ramirez, Chang, Maloney, Levine, \& Beilock, 2016). The present study examines the correlation between math self-concept, test and math anxiety, achievement motivation, and math achievement in 12 to 14-year-old typically developing adolescents.

\section{Self-Concept}

Academic self-concept relates to academic achievement and is defined as the belief in and feelings or perceptions of one's own intellectual and/or academic skills and achievement (Lent, Brown, \& Gore, 1997). Marsh and Martin (2010) found that academic self-concept has direct and indirect effects on academic achievement. This indicates a bidirectional relationship; Increases in academic self-concept lead to increases in academic achievement and vice versa. The findings confirm that academic self-concept plays an important role in influencing academic outcomes. The results are in line with the study by Khalaila (2015) which shows that a high academic self- concept directly relates to better academic achievement.

Specifically, for math, there is a correlation between math self-concept and math achievement in children, (young) adolescents, and young adults (Atunes \& Fontaine, 2007; Luo et al., 2014; McWilliams, Nier, \& Singer, 2013; Parker, Marsh, Ciarrochi, Marshall, \& Abduljabbar, 2013). Math self-concept refers to the belief in and feelings about one's own math competence (Atunes \& Fontaine, 2007). McWilliams and colleagues (2013) found that math self-concept more strongly relates to math achievement than academic self-concept. These findings are in line with the specificity principle of Swann, Change-Schneider, and McClarty (2007) that states that a domain-specific self-concept should be used to predict domain-specific achievement. Hence, there appears to be a correlation between math selfconcept and math achievement. 


\section{Fear}

Another factor that influences academic achievement is test anxiety. Ergene (2011) and Steinmayr, Crede, McElvany, and Wirthwein (2015) examined the relationship between test anxiety and academic achievement in 16 to 17-year-old students. Both studies show that the cognitive component of test anxiety (worrying in test situations), and not the physical component, negatively correlates with academic achievement. Controversially, the highest achieving students report the lowest levels of test anxiety (Putwain \& Daly, 2013). Khalaila (2015) examined the mediating role of test anxiety in the correlation between academic selfconcept and academic achievement. However, the sample of this study consisted of nursing students; test anxiety appeared to be a significant mediator in the correlation between academic self-concept and academic achievement (Khalaila, 2015).

A consistently quoted factor that possibly influences math self-concept and test anxiety is gender. Different studies report higher math self-concepts in boys than in girls (Atunes \& Fontaine, 2007; Skaalvik \& Skaalvik, 2004). In several studies, girls generally report a higher level of test anxiety than boys (Chapell et al., 2005; Ergene, 2011; Kurt, Balci, \& Kose, 2014; Rahafar, Maghsudloo, Farhangnia, Vollmer, \& Randler, 2016); a higher level of test anxiety in girls, and not in boys, correlates with lower academic achievement (Chapell et al., 2005). The correlation between test anxiety and academic achievement is possibly stronger in girls than in boys.

In line with these findings, there appears to be a correlation between math anxiety and math achievement. Math anxiety refers to a feeling of fear or tension that interferes with math achievement (Ashcraft, 2002). Math anxiety appears to be a significant predictor of math achievement (Stankov, Lee, Luo, \& Hogan, 2012). Controversially, children who are experiencing math difficulties can develop math anxiety due to experiences of repeated failure (Ashcraft \& Krause, 2007; Ashcraft \& Moore, 2009). The relation between math anxiety and math achievement is bidirectional (Carey, Hill, Devine, \& Szucs, 2016).

In the literature, different factors are mentioned that can explain or influence the correlation between math anxiety and math achievement. Ashcraft's (2002) study shows that math anxiety leads to ongoing activity in working memory, which in turn interferes with cognitive processing. Ramirez, Gunderson, Levine, and Beilock (2013) examined the relation between math anxiety, problem solving strategies, and math achievement in a group of sevenyear-old children. The results show that math anxiety negatively predicts math achievement, because math anxiety reduces the use of good problem solving strategies. Luo and colleagues (2014) and Wang and colleagues (2015) found a correlation between math anxiety and math achievement in young adolescents. The effect of math anxiety on math achievement appeared to depend on motivation (Wang et al., 2015). In students with high levels of math motivation, an average level of math anxiety facilitated math achievement. In students with a lower level of math motivation, a high level of math anxiety negatively influenced math achievement (Wang et al., 2015). Hence, the activity of working memory (Ashcraft, 2002), the use of good problem solving strategies (Ramirez et al., 2013) and math motivation (Wang et al., 2015) are 
factors that possibly explain or influence the correlation between math anxiety and math achievement.

\section{Motivation}

Another factor that influences academic achievement is motivation. In the literature the terms "academic motivation" and "achievement motivation" are both mentioned. Both are linked to self-determination theory (SDT) that states that someone is intrinsically motivated when he/she is involved in an activity for their own good and for the pleasure and satisfaction that it produces (Deci \& Ryan, 1985). The majority of studies use the term academic motivation; hence, yet, none provide a clear definition of the term. For this reason, the present study uses the term achievement motivation. Achievement motivation is defined as the intrinsic motivation of a child to achieve (Hermans, 2011). Different studies show that there is a correlation between achievement motivation and academic achievement in students in secondary school (Fini \& Yousefzadeh, 2011; Verkuyten, Thijs, \& Canatan, 2001).

Motivation appears to be a frequently studied mediator in the correlation between academic self-concept and academic achievement. The dominant model in the literature states that there is a bidirectional relationship between academic self-concept and academic motivation (Marsh \& Craven, 2005). Guay, Ratelle, Roy, and Litalien (2010) found that autonomous academic motivation mediates the correlation between academic self-concept and academic achievement in students in secondary school. According to the researchers, motivation is the process that explains how academic self-concept relates to academic achievement, which is in line with self-determination theory (SDT; Deci \& Ryan, 1985) and self-concept theory (Marsh, 2007). These results are in line with the study by Areepattamannil (2012) which shows that intrinsic and extrinsic motivation play a mediating role in the correlation between academic self-concept and academic achievement in 16 to 19-year-old adolescents. In addition, Khalaila (2015) examined the mediating role of intrinsic motivation in the correlation between academic self-concept and academic achievement. In line with the results of Areepattamannil (2012), intrinsic motivation appeared to be a significant mediator. Increasing intrinsic and extrinsic motivation may lead to better academic achievement (Areepattamannil, 2012).

\section{This study}

As far as can be determined, there is no study examining the possible mediating role of test and math anxiety and achievement motivation in the correlation between math self-concept and math achievement. This study aims to fill this gap. The central question of this study is: is there a correlation between math self-concept and math achievement in students in the first half of secondary school? In addition, the possible mediation effects of achievement motivation and test and math anxiety are examined. Seven hypotheses are tested (Figure 1). A better notion of the different aspects that are involved with math difficulties can contribute to developing adequate interventions that can reduce and remove the underlying causes of math difficulties (Passolunghi, 2011). 


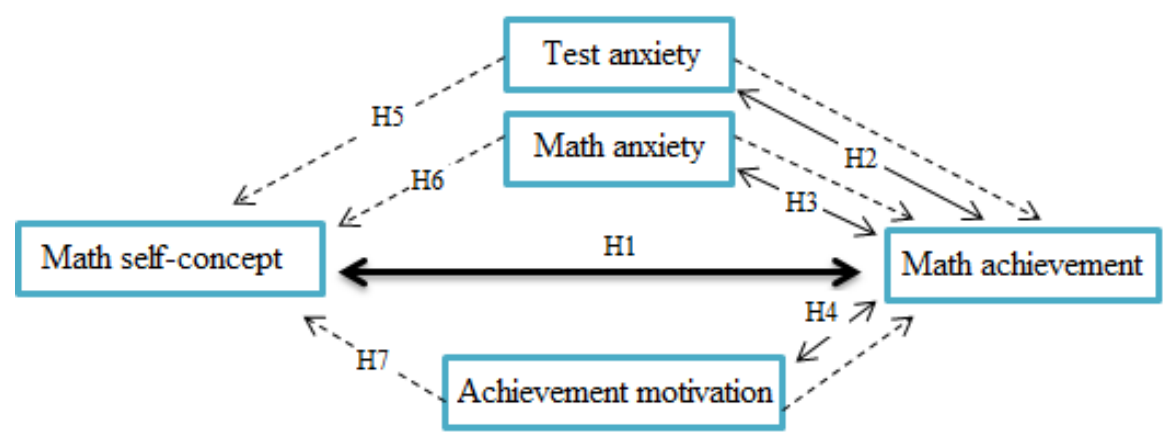

Figure 1. Conceptual model of the correlation between math self-concept and math achievement and the mediating role of test anxiety, math anxiety, and achievement motivation.

\section{Method}

\section{Participants}

Data was gathered from a selected sample from two secondary level high schools. Parents of students from six participating classes received a letter in which they were informed that they could exclude their child from the research project; none of the parents used this option. During the research, eight students were absent due to illness or absence. After importing the data, it was checked for missing entries. These were replaced by the average score on the respective items. When more than $10 \%$ of a scale was not filled in by a student, he/she was excluded from the sample $(\mathrm{N}=1)$. The final sample consisted of 108 students (Nboys $=67$, Ngirls $=41, \mathrm{M}=12.19$ years, $\mathrm{SD}=.41$ ).

\section{Measures}

Math self-concept and math anxiety. Math self-concept and math anxiety were measured using the Math Experience Questionnaire (MEQ; Toll, Van der Beek, \& Van Luit, 2015). The questionnaire computes four scales: adaptive coping strategies, maladaptive coping strategies, self-confidence, and math anxiety. In this study, only two scales were used: self-confidence (15 items) and math anxiety (15 items). Both scales are based on questionnaires from the PISA-research project (Lee, 2009). The items of the self-confidence scale overlap with how math self-concept is measured in comparable studies (Lee, 2009; Luo et al., 2014). A high score on this scale means that a student has confidence in his/her own math skills. Students reported on a 4-point Likert-scale if they agreed with the items ( 1 = totally disagree, $4=$ totally agree). An example of an item in the math self-concept scale is: "I understand math quickly". An example of an item in the math anxiety scale is: "I get nervous when solving math sums". The scale scores were transferred into percentile scores. In this study the reliability of these 
scales were .54 (math self-concept) and .90 (math anxiety), respectively. The reliability of the math self-concept scale was, unlike that recorded in previous studies, insufficient (.72 and .74 respectively; Bakker, 2015; Toll et al., 2015).

Achievement motivation and test anxiety. Achievement motivation and test anxiety were measured with the Achievement Motivation Test for Children (PMTK-2; Hermans, 2011). This questionnaire gives an impression of the child's perception of academic tasks. The questionnaire aims to determine achievement motivation, negative and positive test anxiety, and social desirability. The questionnaire consists of 89 items and can be used with 10 to 16year-old children. The items have two to three answer possibilities. In this study scales of achievement motivation (34 items) and negative test anxiety (14 items) were used. An example of an item on the achievement motivation scale is: "Having a good job in the future is A. unimportant, B. important, C. very important.” A high score on this scale means that a student is sufficiently motivated to achieve. An example of an item on the negative test anxiety scale is: "When I am a little nervous A. I make a lot of mistakes, B. I do not make many mistakes, C. I perform better than whether I am calm.” A high score on this scale means that a student suffers from test anxiety to achieve. The scale scores were transferred into percentile scores. In this study, the reliabilities of the scales were .84 (achievement motivation) and .80 (negative test anxiety), respectively.

Math achievement. The automatizing skills of math operations were measured with the Math Speed Test (TTA; De Vos, 2010). This test consists of a page of addition, subtraction, multiplication, and division fact problems. Students get two minutes per page to solve as many fact problems as possible. The TTA was normed to August of sixth grade. Based on the norms of more specific percentile scores, it can be determined if a student has automatized the math facts sufficiently. The reliability and validity were evaluated as correct (.88; De Vos, 2010).

To determine the content math skills of students, the most recent math achievements of the Dutch standardized mathematics test were measured. This contains the percentile scores concerning four math domains (measurement, relations, numbers, and scale) from the Cito test. This is a national test that is used in the Netherlands to monitor the progress of secondary school children. The total score is determined by the average of these four domains. The reliability was evaluated to be correct (>.90).

\section{Procedure}

All participating students were separately examined once. All questionnaires were conducted in groups in a certain order (TTA, MEQ, PMTK-2), whereby one examiner gave instructions and the other offered individual support in the case of additional questions. During the whole examination students were positioned in a test setup, so they could not copy each other's answers and anonymity was guaranteed. The questionnaires were conducted straight after the TTA test. Whenever a student finished the questionnaires, they were collected and missing items were checked for. If any questions had been skipped, participants were asked to complete them. The total duration of the examination was approximately 50 minutes. 


\section{Results}

In the present study a positive correlation was expected between math self-concept, test anxiety, achievement motivation, and math achievement in secondary school students. Furthermore, it was expected that achievement motivation, test anxiety, and math anxiety should mediate the correlation between math self-concept and math achievement. The math achievement scores, the scores from the Math Experience Questionnaire, and the PMTK-2 were analyzed using SPSS version 20 (Field, 2013).

\section{Math self-concept}

To examine the correlation between math self-concept and math achievement, a Kendall's tau-b correlation test was conducted. This non-parametric test was conducted, because not all conditions of the Pearson $r$ correlation test were met. The variable math selfconcept is not normally divided; the Kolmogrov-Smirnov statistic was significant $(p=.008)$. The Kendall's tau-b conditions of independence and minimal ordinal measurement level were met. The correlation between math self-concept and math achievement was small, positive, and significant, $\tau=.25,95 \%$ BCa BI [.11, .37], $\mathrm{p}<.001$, two-sided, $\mathrm{N}=108$.

To examine the correlation between math self-concept and math achievement, and automatized math skills, Spearman's rho correlation coefficients (rs) were calculated. This non- parametrical test is conducted because the condition of linearity was not accomplished. The correlation between math self-concept and math achievement on the four math domains were small to medium, positive, and significant (see Table 1). The correlations between math self- concept and automatized math skills were small, positive, and significant; rs $=.24,95 \%$ BCa BI [.04, .41], $\mathrm{p}=.013$, two-sided, $\mathrm{N}=108$.

Table 1. Overview of the Spearman Rho Correlations $(\mathrm{N}=108)$

\begin{tabular}{llll}
\hline Correlation & $R s$ & Sign. & $95 \%$ BCa BI \\
\hline MSC and M & $.21^{*}$ & .031 & {$[.01, .38]$} \\
MSC and R & $.24^{*}$ & .012 & {$[.06, .42]$} \\
MSC and N & $.33^{* * *}$ & .001 & {$[.13, .49]$} \\
MSC and S & $.30^{* *}$ & .002 & {$[.11, .47]$} \\
MA and M & -.17 & .080 & {$[-.35, .02]$} \\
MA and R & -.04 & .674 & {$[-.24, .16]$} \\
MA and N & -.19 & .052 & {$[-.36,-.00]$} \\
MA and S & $-.21^{*}$ & .030 & {$[-.38,-.02]$} \\
\hline
\end{tabular}

Note. MSC = math self-concept; $\mathrm{M}=$ measurement; $\mathrm{R}$ = relations; $\mathrm{N}=$ numbers; $\mathrm{S}=$ scale; MA = math anxiety; ${ }^{*} p<.05 ;{ }^{* *} p<.01 ;{ }^{* * *} p \leq .001$.

To examine if age and gender influenced the correlations between math self-concept and math achievement, a Pearson's partial correlation test was conducted. After correcting for age 
and gender, the correlation between math self-concept and math achievement on the domain "measurement" was no longer significant. To further examine the influence of age and gender, a Spearman's rho correlation test was conducted. For both boys and girls, the correlation between math self-concept and math achievements in the domain "measuring and geometry" was not significant; rs =.21, 95\% BCa BI [-.04, .43], $\mathrm{p}=.093$, two-sided, $\mathrm{N}=67$; rs $=.13,95 \%$ BCa BI [-.19, .43], $\mathrm{p}=.406$, two-sided, $\mathrm{N}=41$. This was also the case for the youngest and oldest groups of students, respectively $\mathrm{rs}=.25, \mathrm{p}=.186$, two-sided, $\mathrm{N}=30$; $\mathrm{rs}=.28, \mathrm{p}=.129$, two-sided, $\mathrm{N}=30$. For all other correlations, correcting for age and gender did not cause changes in significance.

Table 2. Overviewof Pearson'sPartial Correlations

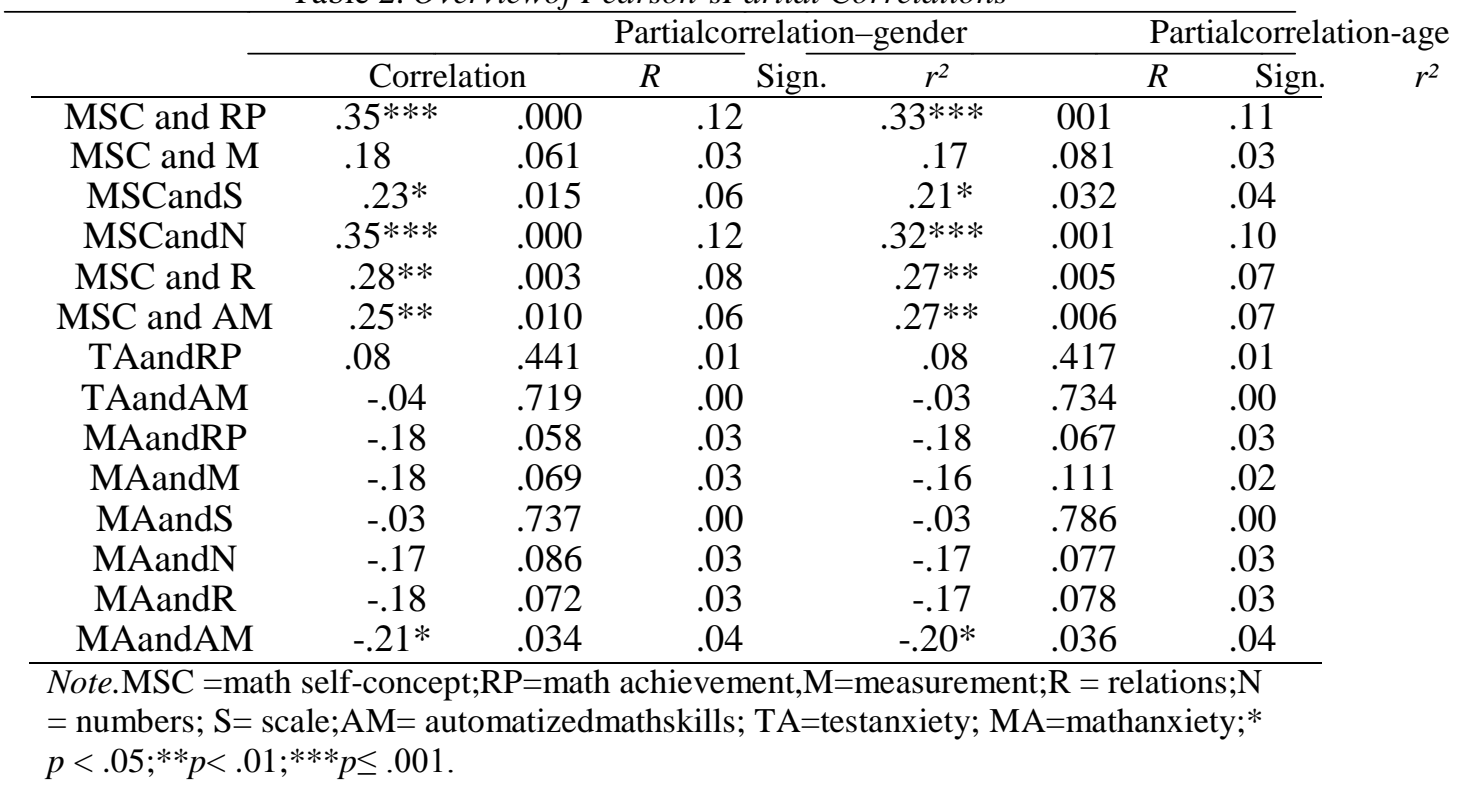

\section{Motivation}

To examine the correlation between achievement motivation, math achievements, and automatized math skills, Spearman's rho correlation tests were conducted. This nonparametric test was conducted because the conditions of normality and linearity were not met. The correlation between achievement motivation and math achievement was not significant; rs $=.00,95 \%$ BCa BI $[-.19, .20], \mathrm{p}=.977$. The correlation between achievement motivation and automatized math skills was also not significant, $r$ s = .14, 95\% BCa BI [-.05, .33], p =.162.

\section{Anxiety}

To examine the correlation between test anxiety and math anxiety, math achievements and automatized math skills, Spearman's rho correlation tests were conducted. This nonparametric test was used because the conditions of normality and linearity were not met. The 
correlation between test anxiety and math achievement was not significant; rs $=.08,95 \% \mathrm{BCa}$ BI [-.11, .28], $\mathrm{p}=.413$, two-sided, $\mathrm{N}=108$.

The correlation between math anxiety and math achievement was small, negative, and significant; rs $=-21,95 \%$ BCa BI [-.38, -.02], $\mathrm{p}=.029$, two-sided, $\mathrm{N}=108$. The correlation between math anxiety and automatized math skills was not significant; rs $=-.19,95 \%$ BCa BI $[-.35, .01], \mathrm{p}=.055$, two-sided, $\mathrm{N}=108$. The correlations between math anxiety and math achievement on the math domain "relations" were small, negative, and significant (Table 1).

To examine if age and gender influenced the correlations between math anxiety and math achievement, a Pearson's partial correlation test was conducted. Having corrected for age and gender, the correlation between math anxiety and math achievement for the domain "relations" was no longer significant. Correction for age and gender resulted in a significant correlation between math anxiety and automatized math skills $(\mathrm{p}<.05)$. To examine the influence of age and gender, Spearman's rho correlation tests were conducted. For both boys and girls, the correlation between math anxiety and automatized math skills was not significant: rs $=-.12$, 95\% BCa BI [-.35, .12], $\mathrm{p}=.342$, two-sided, $\mathrm{N}=67$; rs =-.28, 95\% BCa BI [-.56, .06], $\mathrm{p}=$ .074 , two-sided, $\mathrm{N}=41$. This was also the case for the youngest and oldest groups of students, respectively: $\mathrm{rs}=-.29, \mathrm{p}=.115$, two-sided, $\mathrm{N}=30$; $\mathrm{rs}=-.33, \mathrm{p}=.073$, two- sided, $\mathrm{N}=30$. For both boys and girls, the correlation between math anxiety and math achievement on the math domain "relations" was not significant: rs $=-.17,95 \%$ BCa BI $[-.40, .08], \mathrm{p}=.162$, two-sided, $\mathrm{N}=67$; rs $=-.29,95 \%$ BCa BI [-.53, .04], $\mathrm{p}=.068$, two-sided, $\mathrm{N}=41$. This was also the case for the youngest and oldest groups of students, respectively: $r s=-.22, \mathrm{p}=.237$, two-sided, $\mathrm{N}=$ 30 ; rs $=-.24, \mathrm{p}=.202$, two-=sided, $\mathrm{N}=30$. For all other correlations, correction for age and gender did not cause changes in significance (Table 2).

\section{Mediators}

Given that in the present study achievement motivation and test anxiety do not correlate with math achievement and automatized math skills, these variables were not taken into account in the mediating analyses. To calculate the proportion of variance in math skills that can be explained by math self-concept and math anxiety, a multiple regression analysis (MRA) was conducted. Before conducting this analysis, a few conditions were tested. First, the stemand-leaf plots indicated that the variables math self-concept and math anxiety were not normally distributed; the condition of normality was violated. Boxplots indicated that there were four outliers in the variables math self-concept and math anxiety. These outliers were kept in the sample, because exclusion did not cause changes in significance, and in this way the sample remained as big as possible. Inspection of the normal probability plots and the scatter plot of standardized residuals indicated that the conditions of normality, linearity, and homoscedasticity of residuals were met. Third, there appeared to be one multivariate outlier in the sample; for one participant the Mahalanobis distance was bigger than the critical $\chi^{2} \mathrm{for} \mathrm{df}=$ $2(\alpha=.001)$ of 13.82. This outlier was kept in the sample, for the same reason as given above. Lastly, relatively high tolerances of all predictors indicated that the condition of 
multicollinearity was met. Math self-concept and math anxiety explained $13 \%$ of variability in math achievement; $\mathrm{R}^{2}=.13$, adjusted $\mathrm{R}^{2}=.11, \mathrm{~F}(2,105)=7.59, \mathrm{p}=.001$. Math anxiety appeared not to be a mediator in the correlation between math self-concept and math achievement. Math self-concept was the only variable that explained a significant proportion of unique variance in math achievement (step 1, Table 3).

To examine if age and gender influenced the correlations, hierarchical multiple regression analyses were conducted (MRA). These are combined in Table 3. Correcting for gender (step 2a) and age (step 2b) did not result in changes of any significance. Gender and age were not moderators in the different correlations.

Table 3. HierarchicalMultipleRegressionAnalysisforPredictingMathAchievement with Math Self-Concept,MathAnxiety,Gender,and Age $(N=108)$

\begin{tabular}{lcccccc}
\hline Variable & $B[95 \% \mathrm{CI}]$ & $\beta$ & $s r^{2}$ & $t$ & $p$ & $R^{2}$ \\
\hline Step1 & & & & & & .13 \\
MSC & $.38[.16, .59]^{* * *}$ & .38 & .10 & 3.38 & .001 & \\
MA & $.03[-.19, .25]$ & .03 & .00 & .31 & .757 & \\
Step2a & & & & & & .13 \\
MSC & $.37[.14, .59]^{* * *}$ & .37 & .09 & 3.27 & .001 & \\
MA & $.03[-.20, .25]$ & .03 & .00 & .23 & .820 & \\
Gender & $-.12[-.50, .25]$ & -.06 & .00 & -.65 & .516 & \\
Step2b & & & & & & .13 \\
MSC & $.34[.11, .57]^{* *}$ & .34 & .07 & 2.83 & .004 & \\
MA & $.02[-.21, .24]$ & .02 & .00 & .06 & .882 & \\
Age & $.21[-.22, .64]$ & .10 & .01 & -.69 & .328 & \\
\hline
\end{tabular}

Note.CI = Coincidenceinterval;MSC =mathself-concept;MA=mathanxiety; $* p<.05 ; * * p<.01 ; * * * p \leq .001$.

\section{Discussion}

The present study examined if there is a correlation between math self-concept, test and math anxiety, achievement motivation, and math achievement in students in the first half of secondary school. The aim was to provide a better insight into the different aspects involved with math difficulties, which can help to develop adequate interventions.

In the present study, a positive correlation was found between math self-concept and math achievement, and automatized math skills, which is in line with expectations based on previous studies (Atunes \& Fontaine, 2007; Luo et al., 2014; McWilliams et al., 2013; Parker et al., 2013). The correlation was small for the math domains "measurement" and "relations", and medium for the domains "numbers" and "scale". This means that students who have a greater belief in and better attitudes and perceptions about their own math skills and achievement achieve higher results on substantive and automatized math tasks. After correcting for age and gender, the correlation between math self-concept and math achievement for the domain "measurement" was no longer significant. However, it is not clear 
how age and gender influence this correlation, because research with large groups is lagging. There is possibly a stronger correlation for boys, because in previous studies boys report higher math self-concepts than girls (Atunes \& Fontaine, 2007; Skaalvik \& Skaalvik, 2004).

Unlike expected results based on the studies of Ergene (2011) and Steinmayr and colleagues (2015), in the present study there was no correlation between test anxiety and math achievement, and automatized math skills. In addition, congruent with findings of previous studies (Areepattamannil, 2012; Guay et al., 2010; Khalaila, 2015), there was no correlation between achievement motivation and math achievement, and automatized math skills. A possible explanation refers to the specificity principle of Swann and colleagues (2007) that assumes that a domain-specific concept needs to be used to predict domain-specific results. The concepts of achievement motivation and test anxiety are possibly too general to predict math achievement. In previous studies, for example, general academic motivation and achievement were examined (Areepattamannil, 2012; Guay et al., 2010; Khalaila, 2015).

In line with expectations based on literature (Ashcraft \& Krause, 2007; Ashcraft \& Moore, 2009; Carey et al., 2016; Luo et al., 2014; Ramirez et al., 2013; Stankov et al., 2012; Wang et al., 2015), the current study found a negative correlation between math anxiety and math achievement. This correlation appeared to be only significant for the math domain "relations". There was no correlation found between math anxiety and automatized math skills. This means that students who are experiencing a higher level of math anxiety have lower achievement in math sums in the math domain "relations". After correcting for age and gender, there appeared to be a negative correlation between math anxiety and automatized math skills; the correlation between math anxiety and math achievement for the domain "relations" was no longer significant. However, it is not clear how age and gender influence these correlations, due to the limited size of the number of participants.

Unlike expected results based on the study of Khalaila (2015), in the present study math anxiety was not a mediator in the correlation between math self-concept and math achievement. A possible explanation is that math anxiety is possibly part of the construct of math self-concept. Regression analysis indicated that math self-concept is the only variable which explained a significant proportion of unique variance in math achievement.

One of the current study's strengths is its inclusion of substantive math skills on four different math domains as well as automatized math skills. The diversity of variables included in the study is also a strong point. Both aspects make it possible to create a complete picture and reveal differences.

Aside from its strengths, the current study has different limitations. The first limitation is the relatively small, select sample, which restricts the generalizability of findings. The current study examined six first classes from one high school in The Hague. A second limitation refers to the choice of instruments. Since research on the psychometric qualities of the Math Experiencing Questionnaire is lacking, the results need to be interpreted with caution.

In addition, in the current study, the internal reliability of the math self-concept scale was, unlike in previous studies (Bakker, 2015; Toll et al., 2015), insufficient. A final limitation is that, because of the limited availability of test instruments, it was not possible to measure 
math motivation.

Recommendations for future studies arise from these limitations. First of all, it is recommended that an examination of the psychometric qualities of the Math Experience Questionnaire be carried out. In addition, the construction of the scales math self-concept and math anxiety scales need to be reconsidered, because in the current study they seem to share a huge amount of variance. Finally, it is recommended to include a variety of educational levels and ages, so that possible differences can be revealed. In this way, interventions can be developed that fit better with the respective target group.

The results of the current study imply that math self-concept is an important construct that correlates consistently with content as well as automatized math skills. Stimulating the feelings and beliefs of students in their own math competence could possibly lead to better math achievement.

\section{References}

Areepattamannil, S. (2012). Mediational role of academic motivation in the association between school self-concept and school achievement among Indian adolescents in Canada and India. Social Psychology of Education, 15, 267-386. doi:10.1007/s11218012-9187-1

Ashcraft, M. H. (2002). Math anxiety: Personal, educational, and cognitive consequences. Current Directions in Psychological Science, 11, 181-185. doi:10.1111/14678721.00196

Ashcraft, M. H., \& Krause, J. A. (2007). Working memory, math performance, and math anxiety. Psychonomic Bulletin \& Review, 14, 243-248. doi:10.3758/BF03194059

Ashcraft, M. H., \& Moore, A. M. (2009). Mathematics anxiety and the affective drop in performance. Journal of Psychoeducational Assessment, 27, 197-205. doi:10.1177/0734282908330580

Atunes, C., \& Fontaine, A. M. (2007). Gender differences in the causal relation between adolescents’ maths self-concept and scholastic performance. Psychologica Belgica, 47, 71-94. doi:http://doi.org/10.5334/pb-47-1-71

Bakker, A. (2015). Investeren in rekenprestaties: Het effect van niet-cognitieve factoren en automatiseringsvaardigheden op de relatie tussen rekenprestaties en competentiebeleving [Investment in math success: The effect of non-cognitive factors and automatization on the relation between math scores and belief in competence]. Retrieved from http://dspace.library.uu.nl/handle/1874/317698

Carey, E., Hill, F., Devine, A., \& Szucs, D. (2016). The chicken or the egg? The direction of the relationship between mathematics anxiety and mathematics performance. Mini Review, 6, 1987. doi:10.3389/fpsyg.2015.01987

Chapell, M. S., Blanding, Z. B., Silverstein, M. E., Takahashi, M., Newman, B., Gubi, A., \& McCann, N. (2005). Test anxiety and academic performance in undergraduate and graduate students. Journal of Educational Psychology, 97, 268-274. doi:10.1037/00220663.97.2.268 
Cito (2015). Wetenschappelijke verantwoording Toets $0 \mathrm{t} / \mathrm{m} \mathrm{3}$, tweede generatie. [Scientific justification Test 0-3, second generation]. Arnhem, the Netherlands: Cito.

Deci, E. L., \& Ryan, R. M. (1985). Intrinsic motivation and self-determination in human behavior. New York, NY: Plenum Press

De Vos, T. (2010). Tempo Test Automatiseren. [Math Speed Test]. Amsterdam, the Netherlands: Boom.

Ergene, T. (2011). The relationships among test anxiety, study habits, achievement, motivation, and academic performance among Turkish high school students. Education and Science, 36, 320-330.

Field, A. (2013). Everything you never wanted to know about statistics. In A. Field (Ed.), Discovering statistics using IBM SPSS statistics (pp. 40-88). London, UK: Sage Publications.

Fini, A. A. S., \& Yousefzadeh, M. (2011). Survey on relationship of achievement motivation, locus of control and academic achievement in high school students of Bandar Abbas (Iran). 2nd World Conference on Psychology, Counselling and Guidance. doi:10.1016/j.sbspro.2011.10.168

Guay, F., Ratelle, C. F., Roy, A., \& Litalien, D. (2010). Academic self-concept, autonomous academic motivation, and academic achievement: Mediating and additive effects. Learning and Individual Differences, 20, 644-653. doi:10.1016/j.lindif.2010.08.001

Hermans, J. H. M. (2011). Handleiding Prestatie Motivatie Test voor Kinderen PMT-K-2 (tweede editie). [Manual Achievement Motivation Test for Children PMT-K-2 (second edition)]. Amsterdam, the Netherlands: Pearson.

Khalaila, R. (2015). The relationship between academic self-concept, intrinsic motivation, test anxiety, and academic achievement among nursing students: Mediating and moderating effects. Nurse Education Today, 35, 432-438. doi:10.1016/j.nedt.2014.11.001

Kurt, A. S., Balci, S., \& Kose, D. (2014). Test anxiety levels and related factors: Students preparing for university exams. Journal of Pakistan Medical Association, 64, 12351239. doi:http://dx.doi.org/10.1155/2014/578323

Lee, J. (2009). Universals and specifics of math self-concept, math self-efficacy, and math anxiety across 41 PISA 2003 participating countries. Learning and Individual Differences, 19, 355-365. doi:10.1016/j.lindif.2008.10.009.

Lent, R. W., Brown, S. D., \& Gore, P. A. (1997). Discriminant and predictive validity of academic self-concept, academic self-efficacy, and mathematics-specific self-efficacy. Journal of Counseling Psychology, 44, 307-315. doi:10.1037//0022-0167.44.3.307

Luo, W., Hogan, D., Tan, L. S., Kaur, B., Ng, P. T., \& Chan, M. (2014). Self-construal and students' math self-concept, anxiety and achievement: An examination of achievement goals as mediators. Asian Journal of Social Psychology, 17, 184-195. doi:10.1111/ajsp.12058

Marsh, H. W. (2007). Self-concept theory measurement and research into practice: The role of self-concept in educational psychology. Leicester, UK: British Psychological Society. 
Marsh, H. W., \& Craven, R. G. (2005). A reciprocal effects model of the causal ordering of self-concept and achievement. New support for the benefits of enhancing self-concept. In H. W. Marsh, R. G. Craven, \& D. M. McInerney (Eds.), International advances in self research: New frontiers for self research (pp. 15-52). Greenwich, CT: Information Age.

Marsh, H. W., \& Martin, A. J. (2010). Academic self-concept and academic achievement: Relations and causal ordering. British Journal of Educational Psychology, 81, 59-77. doi:10.1348/000709910X503501

McWilliams, M. A., Nier, J. A., \& Singer, J. A. (2013). The implicit self and the specificitymatching principle: Implicit self-concept predicts domain-specific outcomes. Personality and Individual Differences, 54, 474-478. doi:10.1016/j.paid.2012.09.014

Parker, P. D., Marsh, H. W., Ciarrochi, J., Marshall, S., \& Abduljabbar, A. S. (2013). Juxtaposing math self-efficacy and self-concept as predictors of long-term achievement outcomes. Educational Psychology, 34, 29-48. doi :10.1080/01443410.2013.797339

Passolunghi, M. C. (2011). Cognitive and emotional factors in children with mathematical learning disabilities. International Journal of Disability, Development and Education, 58, 61-73. doi:10.1080/1034912X.2011.547351.

Putwain, D. W., \& Daly, A. L. (2013). Do clusters of test anxiety and academic buoyancy differentially predict academic performance? Learning and Individual Differences, 27, 157-162. doi:10.1016/j.lindif.2013.07.010

Rahafar, A., Maghsudloo, M., Farhangnia, S., Vollmer, C., \& Randler, C. (2016). The role of chronotype, gender, test anxiety, and conscientiousness in academic achievement of high school students. Chronobiology International, 33, 1-9. doi:10.3109/07420528.2015.1107084

Ramirez, G., Chang, H., Maloney, E. A., Levine, S. C., \& Beilock, S. L. (2016). On the relationship between math anxiety and math achievement in early elementary school: The role of problem solving strategies. Journal of Experimental Child Psychology, 141, 83-100. doi:10.1016/j.jecp.2015.07.014

Ramirez, G., Gunderson, E. A., Levine, S. C., \& Beilock, S. L. (2013). Math anxiety, working memory, and math achievement in early elementary school. Journal of Cognition and Development, 14, 187-202. doi:10.1080/15248372.2012.664593.

Skaalvik, S., \& Skaalvik, E. M. (2004). Gender differences in math and verbal self-concept, performance expectations, and motivation. Sex Roles, 50, 241-252. doi:10.1023/B:SERS.0000015555.40976.e6

Stankov, L., Lee, J., Luo, W. S., \& Hogan, D. J. (2012). Confidence: A better predictor of academic achievement than self-efficacy, self-concept and anxiety? Learning and Individual Differences, 22, 747-758. doi:10.1016/j.lindif.2012.05.013

Steinmayr, R., Crede, J., McElvany, N., \& Wirthwein, L. (2015). Subjective well-being, test anxiety, academic achievement: Testing for reciprocal effects. Frontiers in Psychology, 6,1-13. doi:10.3389/fpsyg.2015.01994 
Swann, W., Change-Schneider, C., \& McClarty, K. (2007). Do people's self-views matter? Self-concept and self-esteem in everyday life. American Psychologist, 62, 84-94. doi:10.1037/0003-066X.62.2.84

Toll, S. W. M., Van der Beek, J. P. J., \& Van Luit, J. E. H. (2015). Psychometrische eigenschappen van de Rekenbelevingsvragenlijst. [Psychometric characteristics of the Math experience questionnaire]. Utrecht, the Netherlands: Utrecht University.

Verkuyten, M., Thijs, J., \& Canatan, K. (2001). Achievement motivation and academic performance among Turkish early and young adolescents in the Netherlands. Genetic, Social, and General Psychology Monographs, 127, 378-408. doi:10.1037/a0013155

Wang, Z., Lukowski, S. L., Hart, S. A., Lyons, I. M., Thompson, L. A., Kovas, Y., Petrill, S. A. (2015). Is math anxiety always bad for math learning? The role of math motivation. Psychological Science, 26, 1863-1876. doi:10.1177/0956797615602471 